\title{
Aspectos relevantes en la aplicación de la carga de la prueba en materia civil con ocasión del Código General del proceso de Colombia
}

\author{
Claudia Patricia Navarrete Palomares \\ claudianavarrete30@gmail.com
}

Fecha de recibido: Noviembre 2017 / Fecha de aprobación: Noviembre 2017

\section{Resumen}

En esta investigación, luego de abordarse la noción de prueba, que se traduce en la necesidad imperiosa de acreditar en todos los campos, se emprende el estudio de los aspectos relevantes de ella al interior del proceso judicial, cuyo objetivo primordial es llevar al juez a que tenga plena certeza. Para ello se hace un análisis de la carga de la prueba en el sistema tradicional que ha venido a ser complementado con la carga dinámica. Posteriormente se confrontan, de un lado los poderes de instrucción del juez y del otro el de imparcialidad, para concluir que su iniciativa probatoria debe circunscribirse a complementar la actividad de las partes, pero de modo alguno remplazarla.

\section{Palabras clave}

Prueba /carga / dinámica / estática / aligeramiento /flexibilización / imparcialidad

\section{Abstract}

In this investigation, before addressing the notion of proof which translates into the imperative need to prove in all fields, the study of all relevant aspects is undertaken in the judicial process. The primary objective of which is to bring absolutely certainty to the judge. This requires an analysis of the burden of proof in a traditional system, which has been complimented with dynamic loading. Following this, we find on the one hand, the judge's powers of instruction, and on the other hand, impartiality, to conclude that its probative initiative should be limited to complement the activity of the parties, and in no way replace it.

\section{Key words}

Proof /charge /dynamic / static / lightening / flexibilization / impartiality.

\section{Tabla de contenido}

Introducción. I. Carga de la prueba como carga procesal. I.I La prueba judicial. I.2 La carga de la prueba. I.3 la carga dinámica de la prueba. I.4 La vigencia de la carga estática de la prueba. I.5 Oportunidad. I.6 Casos determinables por el Juez. I.6 Objeto de Contradicción. 2. Valoración del comportamiento de los extremos una vez distribuido el deber de probar. 3. Resultados y aportes. 


\section{Introducción}

La finalidad del presente artículo es tener, en primer lugar, un acercamiento a las nociones de derecho probatorio retomando las propuestas de los procesalistas tradicionales y que esto permita encarar el estudio de prueba judicial, la carga de la prueba y la distribución de la misma para después, como segundo aspecto, efectuar un análisis de la panorámica real actual de la carga dinámica de la prueba con ocasión de la introducción de dicha concesión probatoria en Colombia con el Código General del Proceso (I enero 20I6).

Ciertamente, la regla tradicional prevista en el artículo $177^{122}$ del Código de Procedimiento Civil-disposición procesal vigente hasta el 31 de diciembre de 2015 en el ordenamiento procesal colombiano- estaba encaminada a que quien alegara un hecho debía probarlo -onus probandi-. $Y$ esto estaba soportado en el principio de autorresponsabilidad que enuncia que las partes en el proceso deben probar los hechos que las benefician o, en su defecto, sufrir las consecuencias de su propia inactividad (Devis Echandia, 1970). Empero dicha norma, por virtud del artículo 167 del Código General del Proceso (2012), ha cedido espacio a la tesis de que quien debe probar es aquel que tenga mayor facilidad para ello, permitiéndose el traslado de dicha imposición según las circunstancias en cada caso (Cruz, 2015, p. 398).

De este modo se encuentra que uno de los principios de los cuales se abastece ahora la carga de la prueba es el criterio de flexibilidad (Cruz, 2015, p. 403), según el cual se deja de lado el concepto pétreo de repartimiento de la prueba. Memórese que existían las denominadas reglas de la carga de la prueba que, si bien el ordenamiento jurídico se abstuvo de llamarlas cargas, sí cumplían la función de identificar quién debía probar cierto hecho o circunstancia, y comportaban a su turno la regla de juicio por medio de la cual se le indicaba al juez cómo debía fallar cuando no encontrara la prueba que le diera certeza sobre los hechos, lo cual ha sido morigerado en el sentido de admitir que quien cuente con mayor posibilidad de suministrarla contribuya en su producción, sin que se pueda afirmar que por virtud de esta nueva pauta se dogmatice que la parte a la que beneficia la prueba queda relevada de su deber de probar, sino por el contrario, es en este momento en que las partes deben estar conjuntamente comprometidas en el alistamiento de la prueba cuando así lo disponga el juez. Dicho de otra forma, no significa que la parte tenga la licencia de desplegar un mínimo de actividad en torno al recaudo de su prueba, y que la contraparte quede con el deber de probar lo que aquel afirma $\circ$ niega, pues dicha conducta podría considerarse como negligente y ser calificada como un indicio en su contra, tal como lo establece la norma legal.

122 Decía el artículo 177 del Código de Procedimiento Civil: Incumbe a las partes probar el supuesto de hecho de las normas que consagran el efecto jurídico que ellas persiguen. Los hechos notorios $y$ las afirmaciones o negaciones indefinidas no requieren prueba. 
Entonces, dependiendo de a quien le corresponda probar y de la actividad que se despliega en torno de dicha exigencia surgen dos variables: primero, la carga de la prueba como carga procesal de quien persigue el efecto jurídico de un hecho en relación con una norma, y segundo, la forma en la que el juez valora el comportamiento de los extremos una vez ha distribuido el deber de probar.

Sobre estos dos aspectos se enfila el siguiente escrito. Esto, porque en materia civil, como en las demás áreas del derecho, lo que se persigue por el juez es establecer la verdad de los hechos alegados (Carnelutti, 1955, p. 14); sin embargo, en concreto, cuando se trata de derecho privado es claro que el ejercicio de los poderes de instrucción del juez no se encuentran limitados, ya que aquel tiene ahora no solo el deber de acudir al decreto de pruebas de oficio, sino que, además, cuando advierta un desequilibrio entre las partes, por virtud de los principios constitucionales de igualdad y solidaridad, debe consentir que pruebe aquel que según su criterio se encuentre en mejor posición de probar, dada su cercanía con la prueba, ya sea porque tiene en su poder el objeto de la misma, porque cuenta con circunstancias técnicas favorecedoras, porque ha intervenido de forma directa en los hechos que dieron lugar a la controversia, o simplemente cuando la contraparte se encuentre en estado de indefensión, incapacidad o similares circunstancias.

En cualquier situación lo cierto es que cuando el juez modifique la regla tradicional de carga de la prueba, ya sea por la vía de la prueba de oficio o por el camino de la carga dinámica de la prueba, sin distinción existirá un cuestionamiento respecto de su imparcialidad, que de manera usual provendrá de la parte que asuma el resultado de dicha intrusión. A partir de allí, corresponde debatir el verdadero alcance de los poderes de instrucción del juez, a quien, si bien le corresponde determinar la verdad de los hechos, también debe interferir en la búsqueda de los elementos de juicio (Taruffo, 20I2, p. 218$)$.

Es entonces, que este trabajo investigativo persigue determinar los aspectos que rodearon el aligeramiento del sistema tradicional de carga de la prueba estática, confrontando los poderes de instrucción del juez, autorizados en la última década por vía jurisprudencial y codificados tan solo con el Código General del Proceso en búsqueda de la garantía de los fines del Estado Social de Derecho. Para llevar a cabo esta labor investigativa realizamos una reflexión sobre el estado del arte, la evolución jurisprudencial que presionó la introducción normativa y el análisis de los elementos de la norma, particularmente, luego de escogerse el tema, se consultaron las posiciones doctrinaras alrededor del tema de la prueba, la prueba judicial, la carga de la prueba y la carga dinámica de la prueba, imprimiendo el análisis debido y acorde a una investigación de corte teórica-doctrinaria. 


\section{Carga de la prueba como carga procesal.}

La prueba es la forma de conocimiento de los hechos, es el modo general para efectuar la reconstrucción de aquellos actos del pasado en que se edifican las afirmaciones, de modo tal que toda prueba tiene -sin excepción-como objeto determinar si un hecho ocurrió o no con el fin de controlar la verdad.

La noción de prueba no solo atañe a las ramas del derecho, entre ellas la civil, la penal, la laboral, la administrativa, la constitucional, etc., sino que de forma transversal concierne de igual modo a todo tipo de ciencia o arte que integre el saber humano. Aún en la cotidianidad, todos pretenden probar los hechos, sus actos, los resultados y la causa de estos; todos tienen la necesidad de probar, de convencerse de la realidad, de demostrarles a los demás (Devis Echandia, 1970, p. 9),de tener certeza.

Ahora bien, como dijo Dellepiane, "probar es ir tras los rastros dejados por las cosas, hechos o seres, a estos mismos seres, hechos o cosas" (Dellepiane, 20I2, p. 25), verum est id quod est -la verdad en la cosa, es la cosa misma-, sostiene citando a San Agustín (Dellepiane, 20I2, p. 32).

\section{I La prueba judicial}

Cuando se acude ante un juez para que decida, cada una de las partes está en su deber de probar su verdad, no basta con que se anuncie tener el derecho, sino que aquel se debe acreditar de modo tal que sin la prueba del derecho un derecho no es nada, pues es ella quien le da vida y lo hace útil. Es por esa razón que se dice que la importancia de la prueba en materia judicial es tal que tanto vale no tener derecho como tenerlo y no poderlo probar. $^{123}$

Sin duda, no puede darse inicio a un proceso sin la previa existencia de sucesos o hechos que estén pendientes de probar, respecto de los cuales el jurista se debe dar a la tarea de reconstruir, esto es, hacer una representación del pasado (Devis Echandia, 1998, p. 2) con el fin de determinar que le asiste la razón en el presente, existiendo para ello un conjunto de reglas que definen la forma y modo en que se deben invocar, admitir, practicar y valorar los medios que contienen la prueba y que permitan que el juez llegue a una decisión revestida de certeza.

De esta primera aproximación se infiere que la noción de prueba abarca no solo su manifestación formal, es decir los medios que se usan, sino también su contenido sustancial, o sea los resultados que de esos medios se deducen, lo que se traduce en el convencimiento que con la prueba se produce (Devis Echandia, 1998, p. 9). En otras palabras, la prueba judicial es el conjunto de motivos que de los medios aportados se

${ }^{123}$ Adagio forense. 
derivan y que suministran el conocimiento de los hechos, todo para los fines del proceso, lo cual resume Devis Echandía (1970) en que: "en sentido general, por prueba judicial se entiende, tanto los medios como las razones o los motivos contenidos en ellos; luego, una definición que pretende dar un concepto amplio de la prueba debe incluir ambos puntos de vista" (p. 34).

En síntesis, la prueba judicial es el recaudo reglado de los hechos en que edifican las afirmaciones de los convocados al proceso, que sirve de método para el conocimiento de la verdad, garantizando el debido proceso y la eficacia del derecho sustancial.

\subsection{La carga de la prueba}

Al interior del proceso, los sujetos procesales ostentan derechos y correlativas obligaciones, así como tienen el derecho de probar -esto es, el juez debe atender sus peticiones de orden probatorio-, también tienen la necesidad o carga de acreditar.

Pues bien, esto significa que para la efectividad de un derecho, las partes deben desplegar determinadas conductas que, aunque no son obligatorias, sí suponen que la demostración de su dicho lo perciban como una imposición, pues su desatención obligará a la negativa de sus pedimentos.

El tema de la carga de la prueba ha sido analizado por todos los procesalistas modernos, desde Goldschmidt, Rosenberg y Carnelutti (Donaires, 20I4), quienes lo han ubicado en su doble condición de deber-carga. De ello surge la regla silogística del onus probandi (Medina, 2013, p. II03), esto es, como primera premisa, el que incumbe a las partes probar el supuesto de hecho de las normas que consagran el efecto jurídico por ellas perseguido y, como segunda, según Devis Echandia citado por Donaires (20/4), la existencia de una regla de juicio por medio de la cual se le señala al juez cómo debe fallar cuando no encuentre en el proceso pruebas que le den la certeza requerida sobre los hechos en que debe construir su decisión,donde, en todo caso, el individuo tiene el poder de escoger la realización del hecho que alega.

Lo anterior fue enmarcado como el principio de autorresponsabilidad, el cual tuvo su génesis en el sistema dispositivo a finales del siglo XIX con la Revolución Francesa (Ramírez, 2009, p. 283), y en Colombia a partir del artículo 1757 del Código Civil( I887) y del artículo 177 del Código de Procedimiento Civil(1970). Este último define que es la parte a la que le favorece la que debe aportar al proceso las pruebas de sus alegaciones y de todas aquellas disposiciones que establecen los efectos perseguidos $y$, por ende, es dicho extremo quien obtendrá, en consecuencia, los resultados de su propia inactividad. 
La carga de la prueba fue explicada por Parra (2004) como:

La regla de juicio que le indica a las partes la autorresponsabilidad que tienen para que los hechos que sirven de sustento a las normas jurídicas cuya aplicación reclaman aparezcan demostrados y que, además, le indica al juez cómo debe fallar cuando no aparezcan probados tales hechos" (p. 242).

De acuerdo con lo anterior, el principio de autorresponsabilidad de la carga de la prueba -esto es, la responsabilidad frente así mismo- contiene una regla de juicio para el juez y una pauta para la actividad probatoria de las partes que no determina de modo exclusivo quién debe llevar la prueba, sino quién asume el riesgo de que no se produzca, y esto consiste en una regla de conveniencia (Micheli, 1989, p. 6I).

A su turno, Devis Echandía(1970), haciendo mención del sistema tradicional, destaca que pese a que exista igualdad de las partes en materia probatoria, lo cierto es que según el principio de autorresponsabilidad, los extremos disponen de la libertad para llevar o no al proceso la prueba de los hechos que les benefician y la contraprueba de los que no, lo que asigna adicionalmente una regla de conducta para el juzgador, quien puede fallar de fondo aun cuando falte la prueba del hecho que sirve de soporte a la norma jurídica que debe aplicar, sin que pueda acudir al non liquet, ya que debe resolverse en todo caso.

Con todo, este autor señala que para decidir el asunto, al juez le basta que en el proceso aparezca la prueba, sin importar quién la haya aportado, por lo que considera inexacto el afirmar que la parte gravada con la carga debe suministrar la prueba o que a ella le corresponde llevarla, sino que es mejor indicar que a la parte le asiste el interés en probar tal hecho o evitar que se quede sin prueba, esto es, evadir el riesgo de que falte, pues en caso contrario se traduciría en una decisión adversa.

Sobre este punto propugnó por que la parte debe probar el nacimiento de su derecho o la extinción de su obligación, pero no que tenga la obligación de llevar la prueba, pues ni el juez ni ninguno de los integrantes del proceso puede constreñirlo a ello. En síntesis, el concepto de carga de la prueba se funda, de un lado en la necesidad de cada una de las partes de probar en el proceso lo alegado -conducta que puede ser activa u omisiva-, lo que, de otra parte, debe observar y calificar el juez al ser su principal destinatario, sin que se pueda declarar de forma categórica que es una obligación, ya que su inobservancia no conlleva sanciones procesales o pecuniarias más allá que el despacho negativo de sus pedimentos.

Dicho de otro modo, cuando acuden los sujetos pretendiendo la eficacia de un derecho tienen la carga de probar, siendo una regla para el juzgador y un deber de conducta para las partes: 
Para saber con claridad qué debe entenderse por carga de la prueba, es indispensable distinguir los dos aspectos de la noción: I) por una parte, es una regla para el juzgador o regla de juicio, porque le indica cómo debe fallar cuando no encuentre la prueba de los hechos sobre los cuales debe basar su decisión, permitiéndole hacerlo en el fondo y evitándole el proferir un non liquet, esto es, una sentencia inhibitoria por falta de pruebas, de suerte que viene a ser un sucedáneo de la prueba de tales hechos; 2) por otro aspecto, es una regla de conducta para las partes, porque indirectamente les señala cuáles son los hechos que a cada una le interesa probar (a falta de prueba aducida oficiosamente o por la parte contraria), para que sean considerados como ciertos por el juez y sirvan de fundamento a sus pretensiones o excepciones (Devis Echandia, 1998, p. 150).

En efecto, al interior de un proceso es un deber provechoso de las partes probar los fundamentos de hecho de sus peticiones, bien sea que estas se llamen pretensiones o excepciones, ya que, en todo caso, la inobservancia probatoria les acarrea consecuencias contrarias a lo esperado, $y$ en virtud de ello, cuando no esté probado un hecho que sirve de fundamento a la norma jurídica de la que pretende valerse el extremo, el juez, por regla general, debe fallar en contra de la parte que tenía el interés de probar y que así no lo hizo, en la medida que el litigio se debe resolver aún cuando no exista prueba, evento en el que el juzgador llega a tener certeza, pero de que no se probó lo alegado. Cuando esto ocurre no existe valoración de la prueba, sino que se sopesa la conducta del sujeto procesal, puesaquel no puede negarse a decidir solamente porque la situación de hecho no esté suficientemente aclarada (Devis Echandia, 1970).

No probar completamente o no probar del todo es igual a no probar. Que el juez no alcance el grado de certeza para decidir a favor del actor no significa que no se disponga de fondo, pues, en ambos casos, fenecida la fase probatoria, entra la regla de juicio que impone al juez el deber de juzgar (Micheli, 1989).

\section{I.3 La carga dinámica de la prueba}

Como se mencionó conforme a la concepción tradicional, al actor le corresponde probar los hechos constitutivos que afirma y al demandado los hechos extintivos o modificativos que opone (Donaires, 2014). En otros términos, cuando se trata de carga estática los hechos relevantes invocados por el actor deben ser probados, en tanto que los hechos modificativos, impeditivos o extintivos deben ser demostrados por el demandado, lo que se denomina como reglas de aportación de parte, o reglas de autorresponsabilidad (Ramírez, 2009).

Empero, tal como lo sostiene Balanta (20/3) al hacer un análisis de las tendencias en punto del aligeramiento probatorio, dicha concepción probatoria tradicional es individualista, pues cada parte solo prueba los hechos que le interesan, cuando en el derecho actual lo que se procura es la solidaridad en la producción de la prueba, 
pudiendo trasladarse el deber de probar a la parte contraria de aquella que se beneficia de la prueba, esto en atención a las especiales circunstancias de cada caso.

Esta misma tratadista indicó que el aligeramiento del onus probandi(Balanta, 20I3) ha ido avanzando en las codificaciones, al punto de considerarse la flexibilización probatoria ya no la excepción, sino la regla general, cuando se trata de garantizar la tutela judicial efectiva y el aseguramiento del derecho material bajo la constitucionalización del derecho a la prueba. En este sentido, Goldschmidt (2004) fue el autor de la teoría de la situación jurídica procesal al fijar el término de 'dinamicidad' en el tema de las pruebas, y dijo textualmente:

Los vínculos jurídicos que nacen de aquí (alude al "proceso”) entre las partes no son propiamente relaciones jurídicas (consideración estática del derecho); esto es, no son facultades ni deberes en el sentido de poderes sobre imperativos o mandatos, sino situaciones jurídicas (consideración dinámica del derecho), es decir, situaciones de expectativa, esperanzas de la conducta judicial que ha de producirse $y$, en último término, del fallo judicial futuro; en una palabra: expectativas, posibilidades y cargas. Sólo aquéllas son derechos en sentido procesal -el mismo derecho a la tutela jurídica (acción procesal no es, desde este punto de vista, más que una expectativa jurídicamente fundada)-y las últimas, las cargas “imperativos del propio interés”, ocupan en el proceso el lugar de las obligaciones (p. 15).

Por su parte, en Argentina, Peyrano (20I5) precisó:

La llamada doctrina de las cargas probatorias dinámicas puede y debe ser utilizada por los estrados judiciales en determinadas situaciones en las cuales no funcionan adecuada y valiosamente las previsiones legales que, como norma, reparten los esfuerzos probatorios. La misma importa un desplazamiento del onus probandi, según fueran las circunstancias del caso, en cuyo mérito aquél puede recaer, verbigracia, en cabeza de quien esté en mejores condiciones técnicas, profesionales o fácticas para producirlas (p. 258).

En Colombia, la teoría de las cargas probatorias dinámicas, tras un controvertido desarrollo jurisprudencial, finalmente ha tenido una consagración legal expresa en el artículo 167 del Código General del Proceso (20I2), cuya vigencia completa se verificó el I de enero de 2016.

Así, el concepto de carga dinámica tuvo su génesis en la jurisdicción contenciosa administrativa, cuando el Consejo de Estado a través de la sentencia proferida en el proceso 4700I-23-3I-000-1995-04I64-0I(14786), precisó que en los casos de responsabilidad administrativa médica, donde de manera inicial en el régimen de falla probada, al demandante le correspondía probar todos los elementos de responsabilidad 
por considerarse que se trataba de una obligación de medio, en donde la mera existencia del daño no hacía que se presumiera la falla del servicio. Luego le siguió el régimen de falla de presunta, cuando el mismo órgano máximo de la jurisdicción de lo contencioso administrativo, por medio de la sentencia del 24 de octubre de 1998. Exp. 5902, reiterada en la sentencia del 30 de junio de 1992. Exp. 6897, consideró que en virtud de lo dispuesto en el artículo 1604 del Código Civil(1887), que debía aplicarse en procesos de responsabilidad extracontractual, bastaba con que se acreditara el hecho dañoso y la relación de causalidad, por cuanto, la prueba de la diligencia y cuidado, en los casos de responsabilidad médica, le correspondía al demandado, dando origen a la presunción de falla del servicio. Esta tesis se convirtió en carga dinámica estática, ya que en todos los casos de responsabilidad médica se aplicaba este criterio, entonces, advirtiendo el Consejo de Estado los inconvenientes de esta generalización, se regresó a la regla general de falla probada, pero haciéndose especial énfasis en la prueba indiciaria, donde la conducta de las partes tendría una especial relevancia.

Entonces, en la sentencias Consejo de Estado 4700 I-23-3 I-000-I995-04 I64-0 I (I4786), pionero en distribución dinámica de la carga de la prueba, precisó:

(i) Corresponderá al demandante probar la falla del servicio, salvo en los eventos en los cuales le resulte "excesivamente difícil o prácticamente imposible" hacerlo; (ii) de igual manera, corresponde al demandante aportar la prueba de la relación de causalidad, la cual podrá acreditarse mediante indicios en los eventos en los cuales le "resulte muy difícil -si no imposible- ...la prueba directa de los hechos que permiten estructurar ese elemento de la obligación de indemnizar"; (iii) en la valoración de los indicios tendrá especial relevancia la conducta de la parte demandada, sin que haya lugar a exigirle en todos los casos que demuestre cuál fue la causa real del daño; (iv) la valoración de esos indicios deberá ser muy cuidadosa, pues no puede perderse de vista que los procedimientos médicos se realizan sobre personas que presentan alteraciones en su salud, y (v) el análisis de la relación causal debe preceder el de la falla del servicio.

De forma menos arrojada, la CSJ a través de la sentencia del 5 de noviembre de 2013 dictada en el proceso 2000 I-3103-005-2005-00025-0I reconoció la dificultad de probar en algunos eventos en los cuales no era suficiente lo reglado en el artículo 1604 del Código Civil, señalando que se debía hacer uso de criterios de flexibilización o racionalización probatoria: "teniendo en cuenta las características particulares del caso: autor, profesionalidad, estado de la técnica, complejidad de la intervención, medios disponibles, estado del paciente y otras circunstancias exógenas, como el tiempo y el lugar del ejercicio”. Así, donde fuera evidente la dificultad probatoria para el paciente o sus familiares, se permitió que se atenuara dicha circunstancia; todo lo cual impulsó la inclusión normativa en la última modificación procesal. 
En la primera ponencia de exposición de motivos del artículo 167 del Código General del Proceso (20I2), realizada ante el Senado, Gaceta II4 (20I2), se consignó el siguiente razonamiento:

El derecho fundamental a la prueba implica que a ella se debe acceder sin obligar al necesitado a realizar actos de proeza o que sencillamente a pesar de tener ese derecho, le resulte imposible conseguirla, porque quien la puede desahogar es su contraparte y ésta no tiene interés en hacerlo. Frente a esta realidad y con sustento en el artículo $\mathrm{I}^{\circ}$ de la Constitución Política que se refiere a la solidaridad de las personas, se consagra que cuando a una de las partes le resulte más fácil probar determinados hechos, corresponde a ella demostrarlos. La carga de la prueba mantiene su concepción clásica, pero en determinados casos hay un desplazamiento a una especie de solidaridad dentro de la concepción liberal para que el otro que tiene la facilidad por motivos que no es necesario ni siquiera enunciar, ya que en cada caso y de conformidad con las reglas de la experiencia se llegará a la conclusión, a quién le quedaba más fácil probar un determinado hecho.

De este modo, el texto incluyó una tesis moderna e integradora y dispuso la siguiente fórmula:

Incumbe a las partes probar el supuesto de hecho de las normas que consagran el efecto jurídico que ellas persiguen.

No obstante, según las particularidades del caso, el juez podrá, de oficio o a petición de parte, distribuir la carga al decretar las pruebas, durante su práctica o en cualquier momento del proceso antes de fallar, exigiendo probar determinado hecho a la parte que se encuentre en una situación más favorable para aportar las evidencias o esclarecer los hechos controvertidos. La parte se considerará en mejor posición para probar en virtud de su cercanía con el material probatorio, por tener en su poder el objeto de prueba, por circunstancias técnicas especiales, por haber intervenido directamente en los hechos que dieron lugar al litigio, o por estado de indefensión o de incapacidad en la cual se encuentre la contraparte, entre otras circunstancias similares.

Cuando el juez adopte esta decisión, que será susceptible de recurso, otorgará a la parte correspondiente el término necesario para aportar o solicitar la respectiva prueba, la cual se someterá a las reglas de contradicción previstas en este código.

Los hechos notorios y las afirmaciones o negaciones indefinidas no requieren prueba (sublínea agregada)(Art. 167, Código General del Proceso, 2012). 
Esta consagración dispositiva es la primera en torno del sistema de carga dinámica, en la cual no solamente se dispone la posibilidad de aligeramiento del deber de probar, esto es, que le corresponde probar los hechos a aquel que se encuentre en mejores condiciones de hacerlo, ya sea por el conocimiento de esos hechos, por el contacto directo con aquellos, porque tenga los elementos materiales objeto de prueba, o por cualquier otra circunstancia que le favorezca en la producción de la prueba en cada caso concreto, sino que se prevé adicionalmente quién puede fijar esta nueva distribución y cuándo.

Actualmente, con esta reglamentación, quedaron fijados los siguiente elementos: (i) la regla inveterada de distribución de la carga permanece vigente, en el sentido que la carga de la prueba se encuentra en cabeza del demandante o actor, o en quien alega un hecho, es decir, se sigue usando la regla de la carga estática de la prueba; (ii) no obstante, como consagra el artículo, según el caso, el juez de manera potestativa, de considerarlo necesario, podrá distribuir la carga de la prueba, ya sea al momento de decretar las pruebas o durante todo el periodo probatorio, en todo caso, antes de la sentencia; (iii) la distribución la efectuará de acuerdo con los parámetros claros y concisos que establece la norma; (iv) esta decisión puede ser controvertida a través de recurso de reposición y se pueden solicitar nuevas pruebas, aspectos que ameritan el siguiente análisis.

\section{I.4 Vigencia de la carga estática de la prueba}

La regla de onus probandi, por virtud de la cual quien alega debe probar, continúa reinante; es decir, el sistema de carga de la prueba tradicional no ha perdido vigencia. A quien le beneficien los efectos jurídicos de la comprobación de un hecho está llamado a demostrarlo, lo cual apareja la regla de juicio tradicional que le indica al juez cómo debe fallar cuando no aparezcan probados tales hechos.

Empero, dicha regla general vino a ser contenida con el sistema de carga dinámica de la prueba, pues, indudablemente, la expresión 'podrá' le confiere al juez una discrecionalidad para la distribución de la carga entre las partes, dependiendo de la consideración que en el caso concreto se realice, cuando advierta que existe una asimetría entre las partes o que a alguna le queda más fácil demostrar ciertos hechos.

En suma, como con la introducción de la noción de carga dinámica lo que se pretende es complementar el sistema general de carga estática, claro es que no puede ser aplicada a todos los casos ni de manera obligatoria por el juez, por cuanto no se trata de un deber o una obligación procesal del juez, sino de una carga procesal de la parte cuya responsabilidad se reasigna, aunque respecto de la cual no surge la posibilidad de constreñir a cumplir. 
La estructura clásica, en opinión de Rosenberg (1956),le permite al juez formarse un juicio sobre la pretensión que se hace valer, ya que es una: "instrucción dada al juez acerca del contenido de la sentencia que debe pronunciar" (p.2), la cual debe ser en contra de la parte sobre la que recae la carga de la prueba, pues el juez debe decidir siempre en contra de la parte que afirma cuando la circunstancia discutida no pudo comprobarse, dado que: "soporta la carga de la prueba respecto de los presupuestos del precepto jurídico aplicable” (Rosenberg, 1956, p. II).

Y como lo ha dicho Peyrano, citado por Donaires Sánchez (20I4), esta nueva teoría no desconoce las reglas clásicas de la carga de la prueba, sino que se trata de complementarla o perfeccionarla, flexibilizando su aplicación en todos aquellos supuestos en que quien debía probar según la regla tradicional se veía imposibilitado de hacerlo por motivos completamente ajenos a su voluntad, ya que hay situaciones en las cuales aplicar la regla general conllevaría injusticia, como al demostrar la culpa médica (resaltado fuera de texto).

Por su lado, Tamayo Jaramillo (1993) afirma que:

Ciertamente no se trata de que a priori y como principio general inmutable se invierta la carga probatoria que incumbe a una de las partes. De lo que se trata es de obligar a todos los contendientes a aportar todas las pruebas que estén a su alcance para lograr el conocimiento de la verdad real. En este orden de ideas el juez podrá prescindir, tratándose de la prueba de la culpa, de un principio general que le imponga al demandante probar la culpa del demandado. Pero también deberá prescindir de un principio general de presunción de la culpa, todo depende del caso concreto (p. 91).

\subsection{Oportunidad}

En caso de considerarlo necesario, de manera facultativa, el juez por iniciativa propia o por mediar la petición de la parte, puede modificar la distribución de la carga de la prueba, ya sea en el auto de pruebas o, de no disponer en ese momento con los elementos de juicio necesarios - pues cuenta tan solo con la información que se suministra en la demanda y su contestación-, durante todo el periodo probatorio, pero se destaca que, siempre antes de la sentencia.

Justamente, de manera general en la jurisprudencia, la decisión de adopción de la carga de la prueba se efectuaba en la sentencia, evento en el cual se indicaba que se sorprendía a la partes con una nueva regla de juicio y ya no había forma de controvertir dicha resolución, siendo una de las principales críticas que recibía el sistema de aligeramiento de la carga de la prueba, lo cual quedó zanjado por la norma procesal, superándose de esta forma el reproche que se hacía en este punto a las decisiones del Consejo de Estado. 
Cuando se favorecía la posición probatoria de una de las partes al momento de dictar sentencia, se impedía, como lo afirma la profesora Ramírez Carvajal, una buena "comunicación dialéctica dentro del proceso y en consecuencia desdice de su legitimidad externa, porque la motivación y la argumentación jurídica de la sentencia se fundamentará en criterios particulares, ordenados por el juez" (Ramírez, 2009, p. 302).

\subsection{Casos determinables por el juez}

La distribución se efectuará en aquellos casos en que pueda considerarse que alguno de los sujetos está en mejores condiciones de acreditar determinado hecho. Hay que tener en cuenta que existen litigios en los cuales es la contraparte quien se encuentra en mejor posición de probar que quien introduce la afirmación y quien alega, ya sea por la cercanía con el material probatorio, porque tenga en su poder el objeto de la prueba, o porque se encuentre en circunstancias especiales o haya intervenido en los hechos que dieron lugar al proceso.

Por tanto, en casos donde se requiera un nivel de especialización técnica o científica para la producción del medio de prueba, según las particularidades del caso, como los ejemplos que anunció el artículo 167 del Código General del Proceso(2012), se efectuará una especial distribución al probar.

Sobre esto, en la sentencia C-086 de 2016, a través de la cual se estudió la exequibilidad de un aparte del artículo 167 del Código General del Proceso, se afirmó por la Corte Constitucional, que:

Los eventos mencionados recogen en buena medida las reglas trazadas por la jurisprudencia tanto de la Corte Suprema de Justicia como de la propia Corte Constitucional. Sin embargo, el Legislador facultó a los jueces para evaluar las circunstancias de cada caso y definir si se dan o no los supuestos genéricos para recurrir en ciertos casos a la carga dinámica de la prueba. Esta decisión resulta comprensible y completamente válida, no solo ante la dificultad para anticiparse a nuevas situaciones en una sociedad que presenta vertiginosos cambios algunos tal vez inimaginables-, sino porque son los contornos de cada situación los que permiten evaluar si la igualdad entre las partes se ha visto o no comprometida y se requiere de la longa manus del juez para restablecerla.

De ahí que si permanece el principio general de la carga estática de la prueba, se puede concluir que quien afirma la existencia de una obligación, la existencia de un contrato, la existencia de una deuda, la existencia del pago de una obligación debe suministrar la prueba, ya que continúa vigente el artículo 1757 del Código Civil (1887), conforme al cual incumbe probar las obligaciones o su extinción a quien lo alega. 
La carga dinámica de la prueba, siendo entonces, la posibilidad de morigerar o atenuar el deber de probar por parte del demandante determinada circunstancia, ha sido prevista para casos como los siguientes: cuando se busca establecer la responsabilidad médica por mala praxis (Parra, 20l0); en los casos de simulación; cuando se ejercita la acción pauliana, eventos en los cuales al demandante se le imposibilita demostrar la ocurrencia de algunos hechos o circunstancias relacionadas con la pretensión, tales como la intencionalidad del demandado de causar un agravio al demandante o ánimo defraudatorio; cuando hay levantamiento del velo societario por fraude atribuido a los socios, representantes o administradores de personas jurídicas; cuando se trata de responsabilidad en materia de derecho del consumidor, donde este tiene la carga de probar la existencia del defecto alegado en el bien o servicio y, una vez acreditado, dicha carga probatoria se invierte sobre el proveedor, quien debe demostrar que no es responsable por el referido defecto; cuando haya víctimas del desplazamiento forzado, en actuaciones en las que se trata de demostrar que se ostenta la calidad de desplazado, la cual se presume al encontrarse incluido en el Registro Nacional, por lo que la carga de la prueba se traslada a las autoridades que cuestionan dicha presunción, conforme al artículo 78 de la Ley 1448(20I I); cuando se trate de acciones populares, también se ha aligerado la carga de la prueba, estimando que es al ente estatal a quien corresponde probar que las obras por él realizadas no presentan deterioro que ponga en riesgo los intereses de la colectividad, por contar con profesionales en alta especialidad técnica para estos fines, con base en el principio de solidaridad y colaboración de las partes con la administración de justicia, en procura de una solución justa y la efectividad de los derechos; cuando se esté en un proceso de impugnación de actas de asamblea, no basta la mera afirmación de la parte actora en el sentido que la convocatoria no fue hecha conforme a los estatutos, sino que a la parte demandada le corresponde probar lo contrario, esto es, recae el onus probandi sobre la parte que está en mejores condiciones profesionales, técnicas o fácticas para producir la prueba respectiva.

\subsection{Objeto de contradicción}

La decisión puede ser controvertida a través del recurso y se pueden solicitar nuevas pruebas, de forma que si el juez encuentra que una de las partes está en mejor condición probatoria respecto de la otra, hará la modulación otorgando un término prudente para que la parte a la que le desplaza dicha carga aporte y pida las pruebas que considere necesarias, todo lo cual será objeto de contradicción. También la decisión puede ser objeto de recurso, tanto la determinación que accede como aquella que niega la solicitud de flexibilización de la carga de la prueba.

\section{Valoración del comportamiento de los extremos una vez distribuido el deber de probar}

El concepto de Estado Social de Derecho le impone al juez la responsabilidad de velar por las garantías constitucionales, dentro de las cuales surge el debido proceso, pero ya 
no visto como una mera herramienta, sino como el resguardo inescindible del derecho sustancial, pues el juez no puede ser una parte pasiva en el proceso,como se afirmó por la CSJ en sentencia del I7 de julio de 2006, proceso 4400 I-3 I-03-00 I-I995-02097-0 I, por lo cual, en materia civil se le otorgaron facultades para decretar pruebas de oficio, para impulsar el proceso hacia la verdad, como lo precisó la Corte Constitucional C- 874 de 2003.

De todos los sujetos procesales, quien tiene el deber legal de la búsqueda de la verdad es el juez, para lo cual se le han otorgado poderes de instrucción. En Colombia aún antes de la entrada en vigencia del Código General del Proceso, al juez se le permitía acudir a las pruebas de oficio; con la nueva codificación, lo que era una facultad se consolidó como un deber y se agregó la posibilidad de flexibilizar la carga de la prueba, pudiendo el juez requerir a la parte que él estime para que despliegue una mayor labor probatoria. Esto es, al juez se le otorgó un poder más activo en determinar a quién le asiste la razón.

Por lo demás, para poder acudir a estos poderes de instrucción, debe advertirse una deficiente actividad probatoria de las partes, ya que los poderes que se le otorgan al juez son complementarios y accesorios (Taruffo, 2012),pues, en todo caso, siempre ha sido objeto de crítica que el juez intervenga en materia probatoria, ya que se cuestiona su imparcialidad e independencia porque, como lo afirma Ramírez Carvajal (2009):"cuando el juez favorece la posición de una de las partes, con la inversión de las reglas de la carga de la prueba, pone en duda su imparcialidad, porque vulnera abiertamente el principio de publicidad interna y externa" (p. 302). Es por eso que ha quedado proscrito el variar la carga de la prueba al momento de dictar sentencia. Dicha labor, de considerarse necesaria, se debe efectuar antes, de forma tal que se garantice el derecho de contradicción de las partes, por lo cual, la intervención del juez debe limitarse a ser eventual, indicativa y progresiva (Ramírez, 2009).

Sobre este aspecto se debe establecer que a quien se le confiere el deber superior de buscar la verdad, de igual modo se le deben otorgar los poderes necesarios para acceder a ello, sin que la actividad que despliegue en pro de ello se califique de parcial. Sería tanto como decir que, como afirma Taruffo (20l2), que todos corremos de querer confirmar aquello de lo que estamos convencidos, sin que la solución para ello sea el imposibilitar la búsqueda de elementos o informaciones adicionales para determinar la verdad, o predicar llanamente que existe contradicción entre imparcialidad y la búsqueda de la verdad.

Al respecto, la Coste Suprema de Justicia en sentencia SC-27 del II de agosto de 2015 ha indicado que superado el concepto privatista del derecho civil "que supone una conducta pasiva del juez y un beneficio e interés exclusivo de los particulares", al juez le corresponde emplear todos los poderes que la ley le confiere para verificar los hechos alegados "puesto que su actividad no está guiada por un interés privado como el de los contendientes, sino por uno público -de abolengo superior-que es el de la realización 
de la justicia, uno de los fines esenciales del Estado moderno" (Sentencia CSJ del 4 de marzo de 1998).

Dicho esto, es patente que cuando el juez decreta una prueba o traslada la carga de probar, no se afecta su imparcialidad, pues desconoce cuál va a ser el resultado de aquella, o que aquel le otorgue mayor valor a las que él determina; por lo cual nada se puede reprochar a la iniciativa probatoria del juez, ya que él mismo no desplaza a las partes en su defensa, sino que en la búsqueda de la verdad y en procura de la prevalencia del derecho sustancial y la valoración de la prueba, debe realizarla de forma conjunta.

\section{Resultados y Aportes}

En conclusión, aunque aún se encuentra vigente el sistema de onus probandi, actualmente los principios de igualdad y solidaridad que rigen el Estado Social de Derecho permiten que el juez tenga una labor de instrucción cada vez más amplia. Se transformó la facultad otorgada de decreto de pruebas de oficio, en un deber del juez, y se introdujo de manera positiva la opción del aligeramiento de la carga probatoria dependiendo las circunstancias del caso que tenga en frente.

Este nuevo sistema no pretende relevar del deber de probar de los extremos del litigio, sino que complementa la labor probatoria de las partes, cuando se presente alguna de las circunstancias que de manera enunciativa destaca el artículo 167 de la Ley 1564(2012).

La teoría de las cargas dinámicas señala que hay situaciones distintas a las habituales en las cuales aplicar la regla general generaría injusticias, ya sea porque la contraparte se encuentra en una mejor posición de probar, dada la cercanía con el material probatorio, o haya intervenido en los hechos que originaron el proceso, o se halle en una condición específica que le proporcione al juez el convencimiento de la necesidad de flexibilización, eventos en los cuales se debe inaplicar la regla general y no imponer a la parte que de acuerdo con la ley le incumbe probar, sino a la parte que le queda más fácil acreditar determinado hecho, teniendo en cuenta el acceso a la prueba y el conocimiento técnico para probar determinado hecho.

Por lo demás, en la carga probatoria dinámica no se presenta un desplazamiento total, ya que la solidaridad que se predica del deber de aportar no significa que se releve de responsabilidad a la parte encargada de probar, pues el beneficio tan solo recae sobre aquellos cuando carezca de conocimiento o de posibilidad de acopio.

Este nuevo poder entregado al juez no tiene el carácter de impositivo, pero sí decide efectuar una nueva distribución de la carga de la prueba. Lo cierto es que debe realizarse en las oportunidades procesales previas a la sentencia, ya que le está vedado llevarlo a cabo al decidir la instancia, pues al proceder de tal forma restringiría el derecho de contradicción de la prueba, retornando al sistema imperante previo a la reglamentación. 
La contradicción se puede realizar impugnando la decisión que se adopte en tal sentido, o solicitando nuevas pruebas que acometa la labor probatoria modulada.

Entonces, en síntesis, por virtud de la introducción normativa de la posibilidad de flexibilidad en la carga de la prueba, no solamente se hizo un gran avance al codificar la atenuación del deber de probar, ya que el sistema tradicional de carga estática onus probandi que preveía el Código de Procedimiento Civil cedió espacio al sistema de carga dinámica de la prueba introducido por el Código General del Proceso, lo cual ahora permite una actividad probatoria real -la consecución de la verdad procesal-, ya no con las restricciones de la carga general de probar, sino con la valoración que el juez haga de cada circunstancia que permita hacer una distribución razonable; por lo demás, para la distribución de la carga de la prueba se habilitaron límites que habían sido reclamados, en torno de la forma y oportunidad, y que hacía acreedora a la teoría de la carga dinámica de la crítica de contravenir el principio de imparcialidad del juez al no existir una debida contradicción.

En la búsqueda de la verdad el juez hace uso de los poderes de instrucción, decreta pruebas de oficio y dispone el aligeramiento de la carga probatoria, todo en beneficio de la realización de la justicia como fin principal de orden constitucional.

\section{Referencias Bibliográficas}

Acero, L. G. (Semestre I y II de 20I5). Modificación al régimen de la carga de la prueba en el Código General del Proceso. Responsabilidad Civil y del Estado, (36), I03 - |4I.

Balanta, M. P. (20I3). Justicia material en términos de flexibilidad probatoria. Escritos sobre diversos temas de derecho procesal. Memorias XXXIV Congreso Colombiano de Derecho Procesal.

Carnelutti, F. (1955). La prueba civil. Buenos Aires: Edición Arayú.

Código Civil de Colombia.Ley 57 de 1887. Publicado en el Diario Oficial No. 7.019 de 20 de abril de 1887. Sancionado el 26 de Mayo de 1873 .

Código de Procedimiento Civil. Decreto I400 de 1970. Publicado en el Diario Oficial No. 33150 de 21 de septiembre de 1970. Colombia.

Colombia, Consejo de Estado. Sala de lo Contencioso Administrativo, sección tercera. Sentencia 24 de octubre de 1998, Exp. 5902.

Colombia, Consejo de Estado. Sala de lo Contencioso Administrativo, sección tercera. Sentencia de 30 de junio de 1992, Exp. 6897.

Colombia, Consejo de Estado. Sala de lo Contencioso Administrativo, sección tercera. Sentencia del 28 de abril de 2005. C. P. Ruth Stella Correa Palacio, Proceso 4700I-23-3I-000-1995-04I64-0I(14786). 
Colombia, Corte Constitucional. C-874 de 2003. M. P. Marco Gerardo Monroy Cabra.

Colombia, Corte Constitucional. Sentencia C-070 de 1993. M. P. Eduardo Cifuentes Muñoz.

Colombia, Corte Constitucional. T I74 de 20I3. M. P. Jorge Iván Palacio Palacio.

Colombia, Corte Constitucional. T 264 de 2009. M. P. Luis Ernesto Vargas Silva.

Colombia, Corte Suprema de Justicia. Sala de casación civil. Sentencia del 5 de noviembre de 20I3. M. P. Ariel Salazar Ramírez, Proceso 2000I-3 I03-005-2005-00025-0I.

Colombia, Corte Suprema de Justicia. Sala de Decisión Civil. Sentencia del II de agosto de 2015. M. P. Edgardo Villamil Portilla, Sentencia SC-27 de 2005, Exp. 7367.

Colombia, Corte Suprema de Justicia. Sala de Decisión Civil. Sentencia del 4 de marzo de 1998. M. P. Carlos Esteban Jaramillo Schloss. Sentencia SC-I 2 de 1998, Exp. 4921.

Cruz, H. La carga de la prueba y algunas cuestiones problemáticas en su distribución. Memorias XXXVI Congreso Colombiano de Derecho Procesal.

Dellepiane, A. (2009). Nueva teoría de la prueba (I $0^{\mathrm{a}}$ ed.). Bogotá: Temis.

Devis, H. (1970). Teoría general de la prueba judicial. Buenos Aires: Editorial Zabalia.

Devis, H. (1998). Compendio de derecho procesal. Pruebas judiciales. Tomo II. (10a ed.). Bogotá: Editorial ABC.

Donaires, P. (20|4). Aplicación jurisprudencial de la doctrina de las cargas probatorias dinámica. Derecho y cambio social. (35), I -27.

Giacomette, A. (2009). La prueba en los procesos constitucionales. Bogotá: Señal Editora y Ediciones Uniandes.

Giacomette, A. (20I5). Teoría general de la prueba. Centro colombiano de derecho procesal constitucional. Bogotá: Ibáñez.

Michelli, G. A. (1989). La carga de la prueba. Bogotá:Temis.

Nisimblat, N. (20|4). Derecho probatorio. Bogotá: Doctrina y ley.

Parra, J. (2004). Manual de derecho probatorio ( $14^{\mathrm{a}}$ ed.). Bogotá: Librería ediciones del profesional Ltda.

Parra, M. F. (20I0). Carga de la prueba en la responsabilidad médica. Bogotá: Doctrina y ley.

Peyrano, J. W. (2004). Informe sobre la doctrina de las cargas probatorias dinámicas. Memorias del XXV Congreso Colombiano de Derecho Procesal. 
Ramírez, D. M. (2009). La prueba de oficio. Una perspectiva para el proceso dialógico civil. Bogotá: Universidad Externado de Colombia.

Rosenberg, L. (1956). La carga de la prueba. Buenos Aires: Ediciones jurídicas EuropaAmérica.

Tamayo, J. (1993). Responsabilidad civil médica en los servicios de salud. Medellín:

Biblioteca Jurídica Dike.

Tamayo, J. (1998). Sobre la prueba de la culpa médica. Análisis doctrinal y jurisprudencial. Medellín: Biblioteca jurídica.

Taruffo, M. (20I2). Teoría de la prueba. Lima: Ara Editores.

Taruffo, M. (20I I). La prueba de los hechos. Madrid: Editorial Trotta. 